\title{
Effect of oxidation on cellulose and water structure: a molecular dynamics simulation study
}

\author{
Sathish Kumar Mudedla $(\mathbb{D} \cdot$ Maisa Vuorte $\cdot$ Elias Veijola $\cdot$ Kaisa Marjamaa $(\mathbb{D} \cdot$ \\ Anu Koivula $(\mathbb{D} \cdot$ Markus B. Linder $(\mathbb{D} \cdot$ Suvi Arola $(\mathbb{D} \cdot$ Maria Sammalkorpi $(\mathbb{D}$
}

Received: 21 September 2020/ Accepted: 4 February 2021 / Published online: 3 March 2021

(C) The Author(s) 2021

\begin{abstract}
Enzymatic cleavage of glycocidic bonds is an important, green and biocompatible means to refine lignocellulosic biomass. Here, the effect of the resulting oxidation point defects on the structural and water interactions of crystalline cellulose $\{100\}$ surface are explored using classical molecular dynamics simulations. We show that even single oxidations reduce the connections within cellulose crystal significantly, mostly via local interactions between the chains along the surface plane but also via the oxidation defects
\end{abstract}

Supplementary Information The online version contains supplementary material available at https://doi.org/10.1007/ s10570-021-03751-8.

S. K. Mudedla - M. Vuorte

Department of Chemistry and Materials Science, School of Chemical Engineering, Aalto University,

P.O. Box 16100, FI-00076 Aalto, Finland

e-mail: sathishk238@gmail.com

M. Vuorte

e-mail: maisa.vuorte@aalto.fi

E. Veijola $\cdot$ M. B. Linder $\cdot$ S. Arola

Department of Bioproducts and Biosystems, School of Chemical Engineering, Aalto University, P.O. Box 16100, FI-00076 Aalto, Finland

e-mail: elias.veijola@infinedfiber.com

M. B. Linder

e-mail: markus.linder@aalto.fi

S. Arola

e-mail: suvi.arola@vtt.fi changing the structure of the crystal in direction perpendicular to the surface. Hydrogen bonding on the surface plane of cellulose is analyzed to identify onset of desorption of glucose chains, and the desorption probed. To assess the actual soluble product profile and their fractions resulting from lytic polysaccharide monooxygenase (LPMO) enzyme oxidation on real cellulose crystal samples, we employ High-Performance Anion-Exchange Chromatography with Pulsed Amperometric-Detection (HPAEC-PAD) technique. The findings demonstrate the LPMO oxidation results in soluble glucose fragments ranging from 2 to 8 glucose units in length. Additionally, significantly

K. Marjamaa · A. Koivula

VTT Technical Research Centre of Finland Ltd., Industrial Biotechnology and Food Solutions, Solutions for Natural Resources and Environment, Espoo, Finland e-mail: kaisa.marjamaa@vtt.fi
A. Koivula
e-mail: anu.koivula@vtt.fi
S. Arola
VTT Technical Research Centre of Finland Ltd., Biomass Processing and Products, Solutions for Natural Resources and Environment, Espoo, Finland

\author{
M. Sammalkorpi ( $\square)$ \\ Department of Chemistry and Materials Science \& \\ Department of Bioproducts and Biosystems, School of \\ Chemical Engineering, Aalto University, P.O. Box 16100, \\ FI-00076 Aalto, Finland \\ e-mail: maria.sammalkorpi@aalto.fi
}


more oxidized oligosaccharides were released in LPMO treatment of AaltoCell than Avicel, the two studied microcrystalline cellulose species. This is likely to result from the large reactive surface area preserved in AaltoCell due to manufacturing process. Furthermore, as can be expected, the oxidation defects at the surfaces lead to the surfaces binding a larger amount of water both via direct influence by the defect but also the defect induced protrusions and fluctuations of the glucose chain. We quantify the enhancement of water interactions of cellulose crystals due to the oxidation defects, even when no desorption takes place. The molecular simulations indicate that the effect is most pronounced for the $\mathrm{C} 1$-acid oxidation (carboxylic acid formation) but present also for the other defects resulting from oxidation. The findings bear significance in understanding the effects of enzymatic oxidation on cellulose nanocrystals, the difference between cellulose species, and cleavage of soluble products from the cellulosic material.

Keywords Molecular dynamics - Cellulose · Surface defects - Cellulose oxidation - Water interactions · CHARMM

\section{Introduction}

Cellulose is the most abundant biopolymer on Earth and a key component of e.g. plant biomass which provides the key staple of fermentable sugars for biofuel production and biotechnological products e.g. in polymer, cosmetics and chemical industries (Khalil et al. 2012; Cao et al. 2009; Lindman et al. 2010; Zimmermann et al. 2010; Kontturi et al. 2006). In unprocessed plant biomass, cellulose exists as microfibrils containing $\beta$-1,4-glucose chains in both crystalline order and amorphous regions, surrounded by lignin and hemicellulose. However, most of the applications and chemical products require conversion of pulp into soluble cellulosic derivatives or even monomeric sugars (Kontturi et al. 2006): the most widespread method to obtain these is via cellulase conversion in which several enzymes cooperatively cleave and hydrolyze cellulose to glucose sugars (Paliwal et al. 2012; Jüergensen et al. 2012; Bhat and Bhat 1997; Ward and Moo-Young 1989; Himmel et al. 2007; Horn et al. 2012). Such enzymatic cleavage of the glycosidic bonds in lignocellulosic biomass is a green, biocompatible and highly promising means to modify and refine biomass (Bhat and Bhat 1997; Hayashi et al. 2005; Henriksson et al. 2007).

In crystalline cellulose, the polar hydroxyl groups of the glucose chains form both intra- and interchain hydrogen bonds, which enforces a planar configuration on the glucose rings (Moon et al. 2011; Vermaas et al. 2015; Atalla and VanderHart 1984; VanderHart and Atalla 1987; Sugiyama et al. 1991). The hydrogens present in the glucose rings face up making the top of the chains hydrophobic, while the hydroxyl groups of the glucose units create a hydrophilic environment in between the chains (Lindman et al. 2010; Langan et al. 2005; Nishiyama et al. 2002). The tight packing of cellulose through inter chain hydrogen bonding and hydrophobic interactions (Lindman et al. 2010), as well as the thermodynamic stability of the crystalline regions of cellulose fibers (Cao et al. 2009; Nishino et al. 2004), makes cellulose insoluble in water but also challenging to efficiently refine and process. Water solubility of cellulose derivatives is often achieved through introduction of hydrophilic or ionic groups along the glucose backbone (Isogai 2018; Isogai et al. 2011). On unmodified cellulose, water primarily interacts through polar hydroxyl groups of cellulose at molecular level. This leads to formation of oriented water molecule layers on the crystalline surface of cellulose (Matthews et al. 2006). Via molecular modelling, vibrational spectra and C13 NMR chemical shifts, the structuring of water has been shown to be different on $\{200\},\{010\}$ and $\{110\}$ crystal planes of cellulose (Heiner et al. 1998; Heiner and Teleman 1997; Kubicki et al. 2013).

Relatively recently, enzymes that use an oxidative mechanism to cleave the glycosidic bonds present in natural polysaccharides such as cellulose (Frandsen et al. 2016; Frommhagen et al. 2015; Forsberg et al. 2011, 2014; Quinlan et al. 2011; Harris et al. 2010; Phillips et al. 2011; Beeson et al. 2012), xylan (Couturier et al. 2018; Biely et al. 2016; Frommhagen et al. 2015), xyloglucan (Agger et al. 2014; BennatiGranier et al. 2015; Nekiunaite et al. 2016), glucomannan (Liu et al. 2018; Agger et al. 2014), chitin (Frandsen et al. 2016; Vaaje-Kolstad et al. 2010; Forsberg et al. 2014), and starch (Lo Leggio et al. 2015) were discovered. These enzymes, called lytic polysaccharide mono-oxygenases 
(LPMOs) (Biely et al. 2016; Frandsen et al. 2016; Bhat and Bhat 1997; Busk and Lange 2015; Horn et al. 2012) have the potential to significantly enhance the efficiency of biomass processing especially from the point of view of cellulose (Biely et al. 2016; Frandsen et al. 2016; Kontturi et al. 2006). LPMOs are key components for example in modern bioethanol production (Li et al. 2017; Zhao et al. 2016). LPMOs are copper dependent enzymes for which the active site contains a monocopper center coordinated by histidine and tyrosine amino acids. The enzyme attacks the $\mathrm{C} 1$ or $\mathrm{C} 4$ positions in the sugar units of the polysaccharide to extract hydrogen and for further oxidative cleavage in presence of oxygen and suitable reductant, such as ascorbic acid (Liu et al. 2018).

Molecular simulations at atomistic detail level have been used to examine cellulose crystal structure (Mazeau 2005; Eichhorn and Davies 2006; Vietor et al. 2002; Biermann et al. 2001; Bergenstrahle et al. 2007; Mazeau and Heux 2003; Matthews et al. 2006) and water interactions extensively (Biermann et al. 2001; Heiner et al. 1998; Heiner and Teleman 1997; Kubicki et al. 2013; Mazeau and Rivet 2008; Yui and Hayashi 2007; Yui et al. 2006; Bergenstrahle et al. 2009) with the simulations providing detailed information of the microscopic correlations in cellulose materials. Also enzymatic interactions (Prates et al. 2013; Zhao et al. 2008) and specifically LPMO interactions with the cellulose crystal have been examined (Tan et al. 2015; Vermaas et al. 2015; Liu et al. 2018). In particular, peeling of cellulose chains after oxidation and oxidized products interaction with cellulases have been explored using molecular dynamics simulations (Vermaas et al. 2015). However, the structural changes in cellulose upon oxidative stress, the effect of resulting defects and the influence on overall water interactions remains elusive. As these measure the destabilization and local environment changes due to the LPMO oxidation defects, this information has the potential to aid in designing more effective LPMO setups.

In this study, we assess the effect of oxidation defects both via molecular modelling and analysis of the soluble products from insoluble microcrystalline cellulosic substrates undergoing LPMO catalyzed oxidation. The modelling addresses the influence of the defects on the structure of the cellulose $\{100\}$ surface, the crystal, the water interactions, and the resulting glucose fragment desorption via classical molecular dynamics simulations. The cellulose $\{100\}$ surface is chosen as the LPMO oxidation activity is likely to focus on it. The experimental analysis via High-Performance Anion-Exchange Chromatography with Pulsed Amperometric-Detection (HPAEC-PAD) provides an assessment of soluble products to support the modelling findings. The simulational findings show the cleavage and oxidation of the glycosidic bond induces structural changes on the cellulose crystalline surface that connects with soluble glucose fragments and the enhanced cellulase activity after LPMO treatment. The magnitude of the destabilization and effect on water interactions depends on the location where the oxidation has occurred, with multiple oxidation defects in the chains leading to fragment solubilization at defect separations less than six glucose units. The experimental characterization shows a consistent range of cellooligosaccharides from the examined substrates. The work builds understanding of the effect of LPMOs on the cellulose crystals at microscopic level, connects the oxidation defects with defect-location dependent stronger water binding, and provides a comparison of the enzymatic oxidation at two substrates differing in their accessible and reactive surface area.

\section{Methods}

Computational methods

Classical all-atom molecular dynamics simulations were performed on intact and oxidized cellulose structures in water environment by GROMACS v5.1.5 package (Abraham et al. 2015; Pronk et al. 2013). The CHARMM C36 (Guvench et al. 2011; Mallajosyula et al. 2012; Raman et al. 2010) force field was used for the glucose chains. CHARMM compatible parameters by Vermaas et al. (2015) were used for the oxidized glucose units. Tip3p (Jorgensen et al. 1983) explicit water model was used. Although tip4p (Jorgensen et al. 1983) or tip5p (Mahoney and Jorgensen 2000) water model may better capture hydrogen-bonding features of liquid water (Calero et al. 2015; Vega and Abascal 2011), CHARMM C36 force field has been specifically parametrized for tip3p water model (Guvench et al. 2011; Mallajosyula et al. 2012; Raman et al. 2010). The tip3p suffers from poor reproduction of surface tension, underestimation of 
critical temperature and melting temperature, and underestimation of water dielectric constant and overestimation of self-diffusion constant (Vega and Abascal 2011). However, similar problems persist for all currently existing water models to some extent (Vega and Abascal 2011). Therefore, the results presented here are sensitive to the water model used. CHARMM C36, along with GLYCAM06 and GROMOS 45a4, are currently the most popular force fields used in investigating cellulose structure at atomistic scale $(\mathrm{Li}$ et al. 2018; Oehme et al. 2018; Matthews et al. 2012; Miyamoto et al. 2016). However, it is worth noting that the structures produced by the aforementioned carbohydrate force fields can deviate from experiment and are sensitive to factors such as the initial hydrogen bond conformation and scaling of electrostatic interactions (Oehme et al. 2018; Miyamoto et al. 2016; Matthews et al. 2012). This poses an additional challenge to the interpretation and reproducibility of the results. Additionally, quality experimental structural data on small (nanoscale) diameter cellulose fibers is sparse.

Construction of the initial cellulose crystal structures and the defects in them was as follows. A cellulose I $\beta$ crystal structure was constructed using Cellulose Builder (Gomes and Skaf 2012). The modelled crystal consisted of six glucose chain layers containing 9 glucose chains of 10 glucose units each. Periodic boundary conditions were implemented such that the glucose chains spanned the simulation box and the layers were oriented such that they formed a uniform $\{100\}$ cleavage plane $(\{-100\}$ plane at opposite facet of the crystal). To achieve an "infinite" surface, the terminal glucose monomers on each chain were bonded together across the periodic boundaries of the box. This choice of infinite surface decreases the chain fluctuations but avoids issues rising from free ends or edges. Following the crystal symmetries, the periodic simulation box was monoclinic with box vectors $7.33 \mathrm{~nm}, 5.93 \mathrm{~nm}$, and $10.0 \mathrm{~nm}$, and the corresponding angles $90^{\circ}, 90^{\circ}$, and $96.5^{\circ}$.

As LPMOs oxidize at $\mathrm{C} 1$ and/or $\mathrm{C} 4$ carbons of the glucose ring (Vermaas et al. 2015; Phillips et al. 2011; Beeson et al. 2012; Isaksen et al. 2014; Langston et al. 2011), oxidation induced defects were introduced to correspond to breaking the glycosidic bond at these locations. Defects corresponding to a glucose chain having $\mathrm{C} 1$-lactone, $\mathrm{C} 1$-gluconic acid, C4-keto-aldose, or C4-gem-diol glucose were introduced to the system. These are referred to as C1-keto, C1-acid, C4-keto and C4-diol defects, respectively. The oxidation exposed chain configuration in the crystal is the origin chain of cellulose $\mathrm{I} \beta$. Figure 1 presents the LPMO oxidation reaction pathways and the chemical structures of these defects.

First, we examined the effect of individual oxidation defects (C1-keto, C1-acid, C4-keto, or C4-diol), that is, single point defects, on the cellulose crystal and the surrounding water environment. As the simulation system is periodic, actually the introduction of a single oxidation defect corresponds to introducing a defect density of $0.026 \mathrm{~nm}^{-2}$ to the system. As empirical carbohydrate forcefields, such as CHARMM C36, have been shown to have some initial configuration bias (Oehme et al. 2018; Miyamoto et al. 2016; Matthews et al. 2012), three replicates of the C1-acid, C1-keto, and C4-diol and two replicates of the C4-keto systems with single oxidation defect were simulated. The results reported here are averaged over the equivalent simulated systems unless otherwise specified. To ensure the findings are not subject to artefacts resulting from unintended cross-interactions of the introduced defects via the periodic boundary conditions, the response of the system was checked against systems with two point defects instead of one, that is, systems with two times larger defect density. For this finite size check, the defect density was increased such that a 2 nd defect was set 4 glucose chains apart from the original pair at a glucose ring located diagonally along the periodic cellulose surface plane with respect to the original defect. The 2 nd defect was set as far as possible from the original defect site in the periodic simulation box. Introduction of the two oxidation defects on the surface corresponds to an average defect density of $0.052 \mathrm{~nm}^{-2}$. The locations of the defect sites on the cellulose surface have been illustrated in Fig. 2.

Next, after this examination of the effects of noninteracting defect pairs, we turned attention to defect pairs that we expected to have correlated effects on the cellulose crystal. Two defects were set in the same glucose chain at varying separations (varying distance in glucose rings) or two defect pairs were set at different chains but now only 1 glucose chain separated. The locations of the defects on the cellulose surface have been illustrated in Fig. 2. In all simulation systems, the simulation box was filled with water 


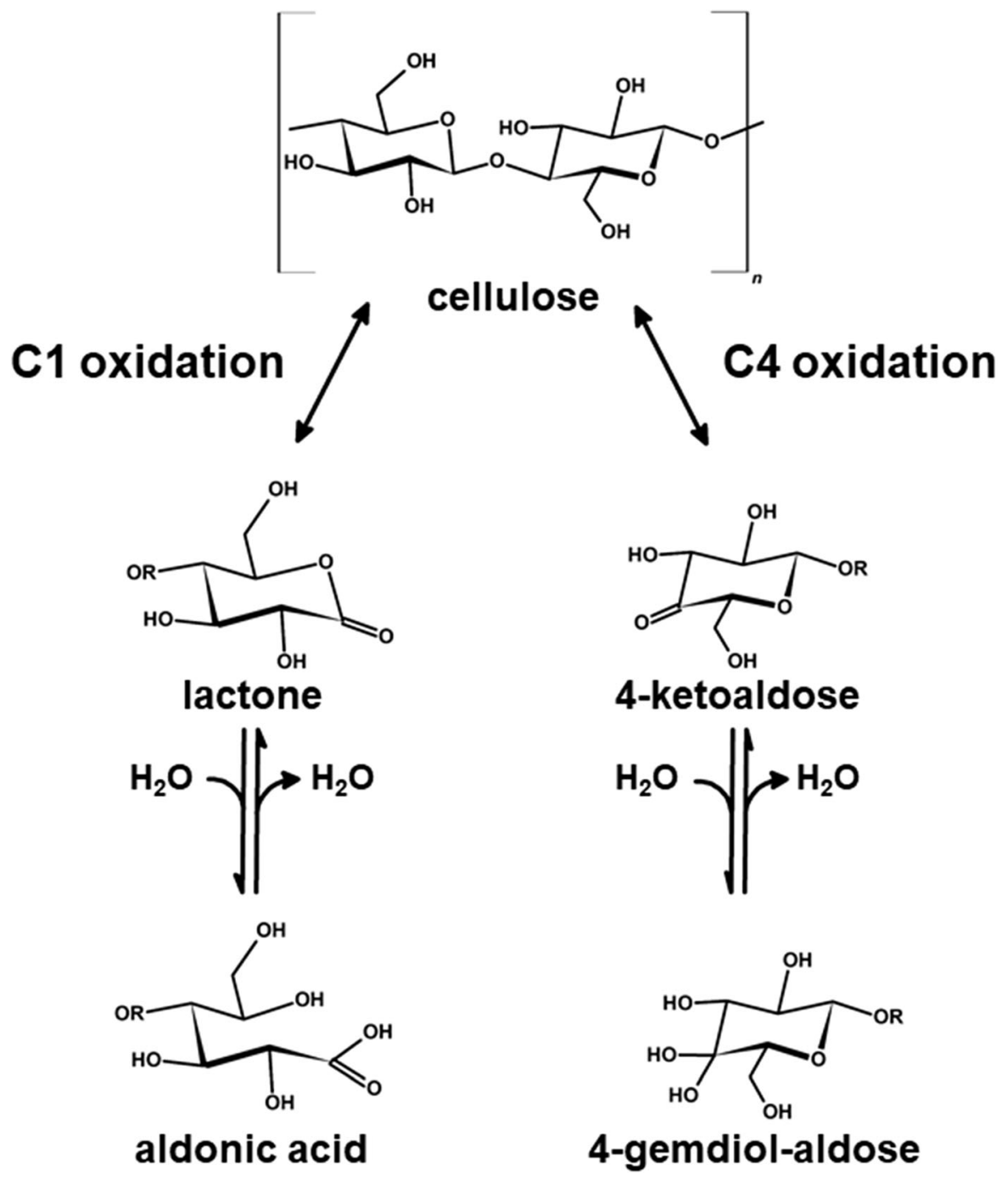

Fig. 1 Reaction pathway for the oxidation of the cellobiose unit via $\mathrm{C} 1$ or $\mathrm{C} 4$ oxidation. In this work, the oxidative modifications to the glucose ring corresponding to the structures of lactone,

and the negative charge of cellulose for C1-acid defects was neutralized by $\mathrm{Na}^{+}$counter-ions.

The constructed cellulose and the surrounding water were initially relaxed using the steepest descent method. For initial $5 \mathrm{~ns}$ NPT relaxation, the glucose ring carbon atoms of the cellulose crystal were position restrained. For the subsequent $150 \mathrm{~ns}$ NPT run, the cellulose crystal was not constrained. For both NPT runs, the temperature was controlled with the vrescale thermostat (Bussi et al. 2007) with a reference temperature of $300 \mathrm{~K}$ and $\tau_{T}=0.1 \mathrm{ps}$. The pressure was set to 1 bar using the isotropic Parrinello-Rahman aldonic acid, 4-ketoaldose, and 4-gemdiol-aldose are referred to as C1-keto, C1-acid, C4-keto, and C4-diol, respectively

barostat (Parrinello and Rahman 1981; Parrinello et al. 1983) with $\tau_{p}=2.0 \mathrm{ps}$ and compressibility of $4.5 \times 10^{-5} \mathrm{bar}^{-1}$. The bonds between heavy atoms and hydrogens were constrained at equilibrium lengths using LINCS (Hess et al. 1997) algorithm. LennardJones interactions were truncated at $1.2 \mathrm{~nm}$. Particle Mesh Ewald (Darden et al. 1993) method was employed for the long-range electrostatic interactions. The equations of motion were integrated using a leapfrog algorithm and a 2 fs time step.

The analysis were carried out for the last $50 \mathrm{~ns}$ of simulations, which here corresponds to 50000 saved 


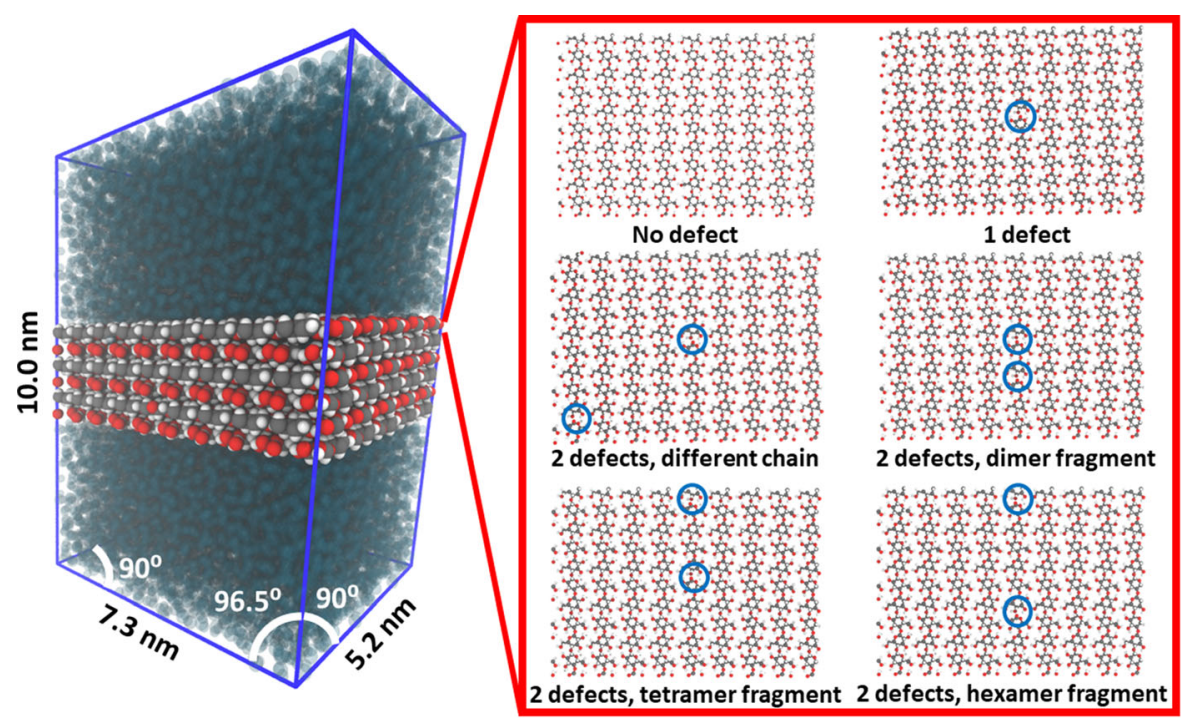

Fig. 2 Visualization of the simulated system. For the simulations, the $\{100\}$ interface of the cellulose slab was modified by introducing either none (no defect), one or two oxidation

trajectory frames. The initial $100 \mathrm{~ns}$ of the trajectories were disregarded in the analysis as the cellulose crystal needed time to relax. The trajectories were analyzed using tools available in GROMACS v.5.1.5 (Abraham et al. 2015; Pronk et al. 2013) package. Unless otherwise stated, hydrogen bonds are used as the measure of residues having contact. For analysis, the existence of a hydrogen bond was determined based on a cut-off distance of $0.35 \mathrm{~nm}$ between the acceptor and the donor atoms of the hydrogen bond as well as a cut-off of $30^{\circ}$ for the hydrogen-donor-acceptor angle. Solvent accessible surface area was calculated using a probe radius of $0.14 \mathrm{~nm}$. VMD (Humphrey et al. 1996) was used for visualization.

Experimental materials and methods

\section{Enzyme and cellulose substrates}

Avicel ${ }^{\circledR}$ PH-101 was purchased from Sigma Aldrich. AaltoCell ${ }^{\mathrm{TM}}$ was kindly provided by Prof. Dahl (Aalto University) and produced according to Vanhatalo and Dahl (Vanhatalo and Dahl 2014) from never-dried bleached hardwood kraft pulp. LPMO enzyme AA9D from white rot fungus Phanerocaheta chrysosporium (Westereng et al. 2011) (Pc AA9D), was kindly provided by Prof. Igarashi (University of Tokyo). modifications either at $\mathrm{C} 1$ or $\mathrm{C} 4$ carbon of a glucose unit. The different oxidation site configurations are identified by the blue circles in the subfigures

\section{Treatment of cellulosic substrates with LPMO}

The cellulosic substrates (Avicel or AaltoCell) were treated with LPMO enzyme (Pc AA9D) using cellulose concentration of $0.1 \mathrm{w} / \mathrm{v} \%$ in $10 \mathrm{mM}$ HEPES $\mathrm{pH}$ 7 buffer. The LPMO concentration in the reaction was $0.8 \mu \mathrm{M}$. Reaction were carried out with or without $1 \mathrm{mM}$ ascorbic acid as reductant. Sample volumes of $0.25 \mathrm{ml}$ were incubated at $50^{\circ} \mathrm{C}$ in $1400 \mathrm{rpm}$ Thermomixer (Eppendorf) for $24 \mathrm{~h}$. Enzymes were inactivated by increasing the $\mathrm{NaOH}$ concentration to $0.2 \mathrm{M}$. Supernatants were removed by centrifuging at $16000 \mathrm{~g}$ 's for $4 \mathrm{~min}$ and filtrated through $0.22 \mu \mathrm{m}$ (Millipore-GV). Supernatants were stored in $-80{ }^{\circ} \mathrm{C}$ for further analysis.

\section{HPAEC-PAD}

Qualitative analysis of the soluble oligosaccharides was carried out with Dionex ICS 5000+ high performance anion exchange chromatography (HPAEC) with pulsed amperometric detection (PAD). Samples were filtrated through $0.22 \mu \mathrm{m}$ (Millex-GV Durapore ${ }^{\circledR}$ ) filter and stored at $10{ }^{\circ} \mathrm{C}$ prior analysis. Sample amount used in the analysis was $10 \mu \mathrm{l}$. The analysis was done according to (Westereng et al. 2013) with following modifications: The column was a CarboPac PA1 $4 \times 250 \mathrm{~mm}$ column coupled with a CarboPac 
PA1 $2 \times 50 \mathrm{~mm}$ guard column (Thermo Scientific) instead of CarboPac PA1 $2 \times 250 \mathrm{~mm}$, and the flow rate was $1 \mathrm{ml} / \mathrm{min}$ instead of $0.25 \mathrm{ml} / \mathrm{min}$. Chromatographic data was analysed using the Chromeleon ${ }^{\mathrm{TM}}$ Chromatography Data Systems software and chromatograms modified with Microsoft Excel.

\section{Results and discussion}

First, the effects of single C1-keto, C1-acid, C4-keto, or C4-diol defects on the cellulose crystal structure and water interactions were assessed simulationally via comparison to intact, defect free cellulose crystal. Figure 3 shows the simulation snapshots from the end of the simulated trajectories of single point defect systems. Oxidation breaks the glycosidic bond between two subsequent glucose rings resulting in a significant structural deformation and protrusion of the chain around the defect site to the surrounding aqueous environment. This enhances water-cellulose contacts, and at high enough defect concentration connects with fragment solubility. The protrusion is particularly notable for the $\mathrm{C} 1$-acid defect, which in addition to breaking the glucose-glucose glycosidic bond, also opens the glucose ring.

Oxidation of the cleaved glucose chain introduces new, hydrophilic functional groups that can hydrogen bond with the solvent water. Additionally, the broken bond between two glucose rings creates two flexible chain ends that can interact with surrounding water. The breaking of the glycosidic bond and introduction of additional functional groups also causes steric clash, which further contributes to deformation of the cellulose surface. Altogether, given a sufficiently high defect density, the resulting protrusions may lead to disassociation of glucose oligomers from the cellulose surface.

Quantitatively, the structural integrity of the defective cellulose crystals as well as individual glucose chains was assessed via time evolution of root mean square deviation of the cellulose crystal coordinates. The data is presented as Figure S1 of Supporting Information. After initial relaxation of the crystal, the structural RMSD converges at a constant level indicating the crystal does not change in shape or form after $50 \mathrm{~ns}$ simulation. It is clear that introducing a single oxidation point defect on the cellulose surface does not significantly change the structure of the entire crystal. However, local chain fluctuations, especially in the case of the $\mathrm{C} 1$-acid defect, are present.

Locally, the structure of the cellulose crystals is stabilized due to the van der Waals interactions and intralayer hydrogen bonds between glucose rings (Langan et al. 2005; Larsson et al. 1997; Nishiyama et al. 2002). The oxidation of a glucose ring significantly alters these interactions. Figure 4 shows the relative decrease in number of hydrogen bonds due to the oxidation defects when compared to intact, defect free cellulose crystal. The hydrogen bonds reported here include both intralayer and interlayer hydrogen bonds. Based on literature, hydrogen bonds within $\mathrm{I} \beta$-cellulose crystals are limited to intralayer hydrogen bonds, with no existing evidence of interlayer bonding (Nishiyama et al. 2002, 2008). However, current empirical forcefields have been shown to sample conformational space differing from that of the I $\beta$-cellulose crystal structure, as well as, introduce artefact interlayer hydrogen bonding patterns (Matthews et al. 2012; Oehme et al. 2015). Regardless of oxidation type, the number of hydrogen bonds is slightly reduced in comparison to defect-free cellulose. The decrease in contacts corresponds with structural weakening of the cellulose crystal.
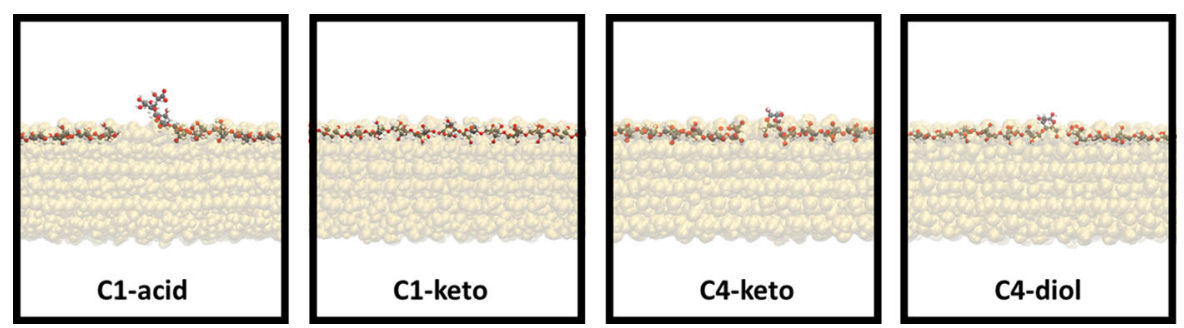

Fig. 3 Visualizations of the oxidized glucose (single defect) chain on the $\{100\}$ cellulose surface after 150 ns of simulation. Figure 1 shows the chemical structures and Fig. 2 the detailed molecular conformations of the defects 


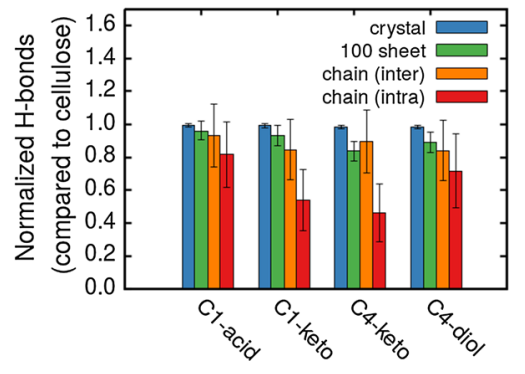

Fig. 4 Hydrogen bonding within oxidized cellulose crystal, outermost oxidized $\{100\}$-sheet, and single oxidized glucose chain. The results have been normalized with respect to unoxidized cellulose. Error bars represent \pm standard deviation

However, the decrease in hydrogen bonds is nonexistent when assessed against the entire crystal: the effect of a single point defect is limited only to a close local environment. To capture the localized changes around oxidized units, we have calculated the interchain and intrachain hydrogen bonding for the oxidized glucose chain on the outermost glucose chain sheet, see Fig. 4. Compared to unoxidized cellulose, the number of both interchain and intrachain hydrogen bonds decreases with oxidation of the glucose chain, see Fig. 4. The difference is most notable in intrachain hydrogen bonds upon introduction of C1-keto or C4keto groups.

Inter and intrachain hydrogen bonds of oxidized glucose chains involve different hydroxyl groups. We focus here on the hydrogen bonding of the three hydroxyl groups on the cellulose surface layer. The different groups are denoted here as $\mathrm{O} 2 \mathrm{H} 2, \mathrm{O} 3 \mathrm{H} 3$ and O6H6 based on their location in the glucose ring, see Fig. 5 for the nomenclature connection to chemical structure. Figure 6a presents the hydrogen bonding data per each of the hydrogen bonding groups for the oxidized cellulose chain compared to equivalent data for unmodified cellulose. The absolute numbers here are interactions model dependent and should be regarded as qualitative. Regardeless of the oxidation type, the number of $\mathrm{O} 3 \mathrm{H} 3$ mediated hydrogen bonds increases significantly in comparison to unmodified cellulose. Furthermore, most of the hydrogen bonding decrease upon oxidation occurs specifically for the $\mathrm{O} 2 \mathrm{H} 2$ and $\mathrm{O} 6 \mathrm{H} 6$ hydrogen bonds for all examined oxidation types. Together, these observations imply that the peeling of chains from cellulose involves first breaking of hydrogen bonds formed by the $\mathrm{O} 2 \mathrm{H} 2$ and O6H6 groups, followed by the formation of new

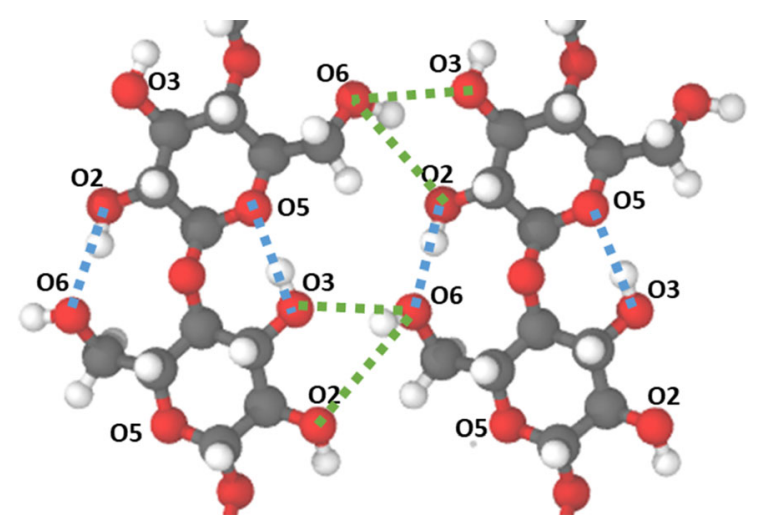

Fig. 5 Inter- and intrachain hydrogen bonding pattern on $\{100\}$ cellulose surface. Dashed lines denote possible hydrogen bonds, with intrachain bonds in blue and interchain bonds in green. In this work the hydroxyl groups of $\mathrm{O} 2, \mathrm{O} 3$, and $\mathrm{O} 6$ oxygens are referred to as $\mathrm{O} 2 \mathrm{H} 2, \mathrm{O} 3 \mathrm{H} 3$, and $\mathrm{O} 6 \mathrm{H} 6$ respectively. The hydrogen bond decomposition consideration is limited to hydrogen bonding of the three hydroxyl groups within the cellulose surface layer

hydrogen bonds by the $\mathrm{O} 3 \mathrm{H} 3$ groups. Subsequent breaking of the formed $\mathrm{O} 3 \mathrm{H} 3$ hydrogen bonds lead to the extraction of glucose chains from cellulose.

Cellulose crystal surface-water interaction has been demonstrated to play a key role in the crystal interactions but also for enzymatic cleavage (O'Neill et al. 2017; Chundawat et al. 2011; Kumar et al. 2010; Felby et al. 2008; Bellesia et al. 2012). Water adsorption on the cellulose crystal surface is influenced especially by the hydrophilic $(\mathrm{O} 2 \mathrm{H} 2, \mathrm{O} 3 \mathrm{H} 3$ and O6H6) and hydrophobic $(-\mathrm{CH})$ sites available on the cellulose surface. As can be seen from the simulation snapshots in Fig. 3, significant protrusion and twisting of the oxidized cellulose can be expected. Based on Fig. 7, oxidation notably increases the solvent accessible surface area of the cellulose $\{100\}$ crystal surface in comparison to the unoxidized cellulose surface. This means, the availability of both hydrophilic and hydrophobic groups to the solvent changes significantly. The increase in solvent accessible surface is most prominent for the $\mathrm{C} 1$-acid, where protrusion of the chain from the cellulose surface was most prominent. The significant change in crystal structure upon oxidation may also allow water to further penetrate inside the cellulose crystal.

Water on the $\{100\}$ cellulose surface forms a distinct two layer ordered structure (Nawrocki et al. 2015), as apparent from the density profile presented in Fig. 8, see inset $b$. The density profile for water is 


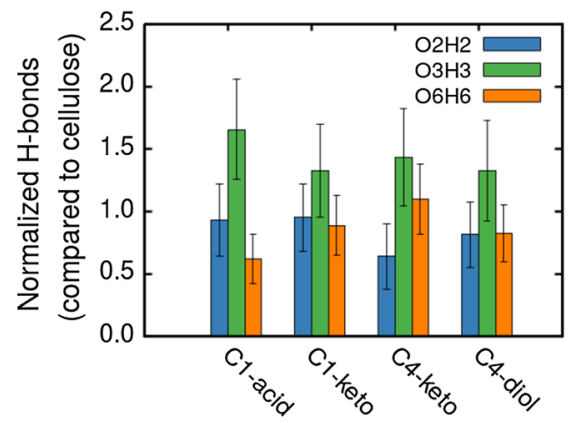

a

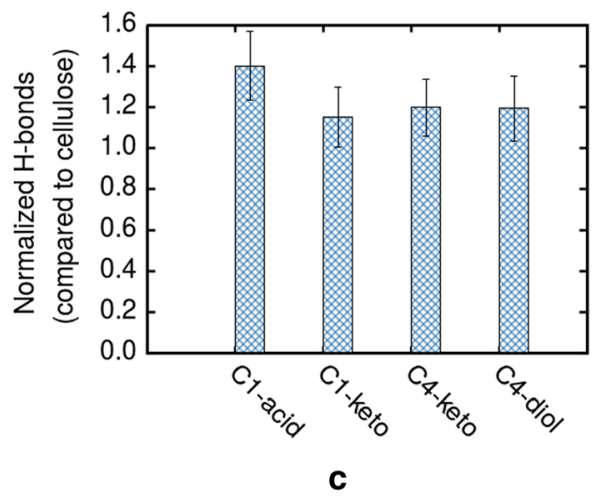

Fig. 6 Hydrogen bonds formed by the $\mathrm{O} 2 \mathrm{H} 2, \mathrm{O} 3 \mathrm{H} 3$, and $\mathrm{O} 6 \mathrm{H} 6$ hydroxyl groups of the oxidized cellulose chain with (a) the cellulose surface and (b) water normalized by hydrogen bonding within unoxidized surface. (c) Hydrogen bonds formed between oxidized cellulose chain and water normalized by hydrogen

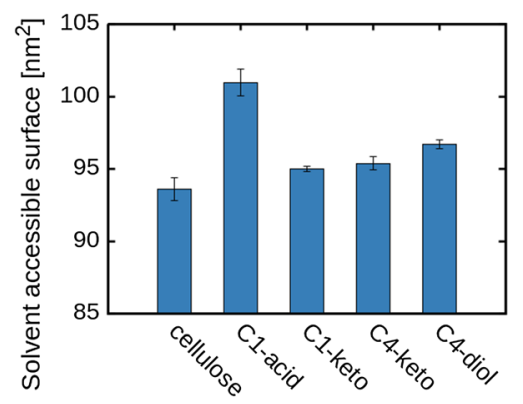

Fig. 7 Solvent accessible surface area at the $\{100\}$ interface for unoxidized and oxidized cellulose (single oxidation defect)

similar on both sides of the cellulose crystal that correspond to the $\{100\}$ and $\{-100\}$ crystal planes, and a single oxidation defect on the surface does not significantly affect the layered water structure. However, a small increase in the amount of water at the $\{100\}$ interface can be perceived upon oxidation. In particular, the oxidized surfaces have a greater water
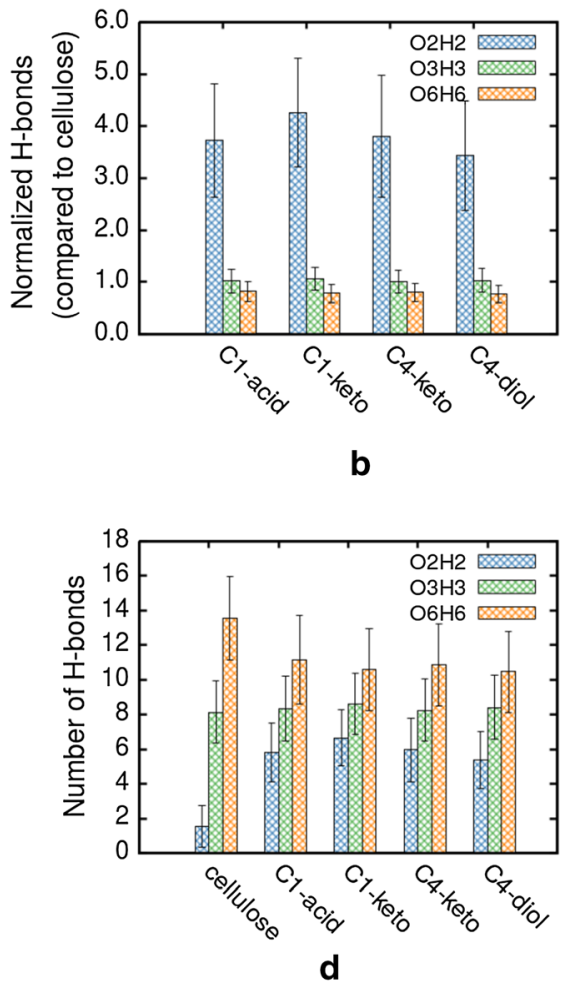

bonding by unoxidized cellulose. (d) Total number of hydrogen bonds formed by the $\mathrm{O} 2 \mathrm{H} 2, \mathrm{O} 3 \mathrm{H} 3$, and $\mathrm{O} 6 \mathrm{H} 6$ hydroxyl groups with water. The data is an average over the replicate simulations, with errorbars representing \pm standard deviation

density in first and second water layers compared to intact cellulose. Additionally, oxidation allows small amounts of water to penetrate into the cellulose crystal, see Fig. 8 inset $c$, which may contribute to loss of structural integrity.

Adsorption of water at the cellulose surface occurs primarily at the exposed hydroxyl groups via hydrogen bonding (Nawrocki et al. 2015; Li et al. 2011). Figure $6 \mathrm{c}$ shows that the total number of hydrogen bonds between the glucose chain and water increases upon oxidation. This supports the previous finding of more water molecules being present at the oxidized cellulose-water interface. The increase in hydrogen bonding is largest for $\mathrm{C} 1$-acid defect, which caused significant protrusion of the chain from the cellulose surface, see Fig. 3. Figure $6 \mathrm{~b}$ plots the number of hydrogen bonds between the oxidized cellulose chain and water per each of the main interacting hydroxyl groups of cellulose, that is, $\mathrm{O} 2 \mathrm{H} 2, \mathrm{O} 3 \mathrm{H} 3$, and $\mathrm{O} 6 \mathrm{H} 6$. The data has been normalized using corresponding 

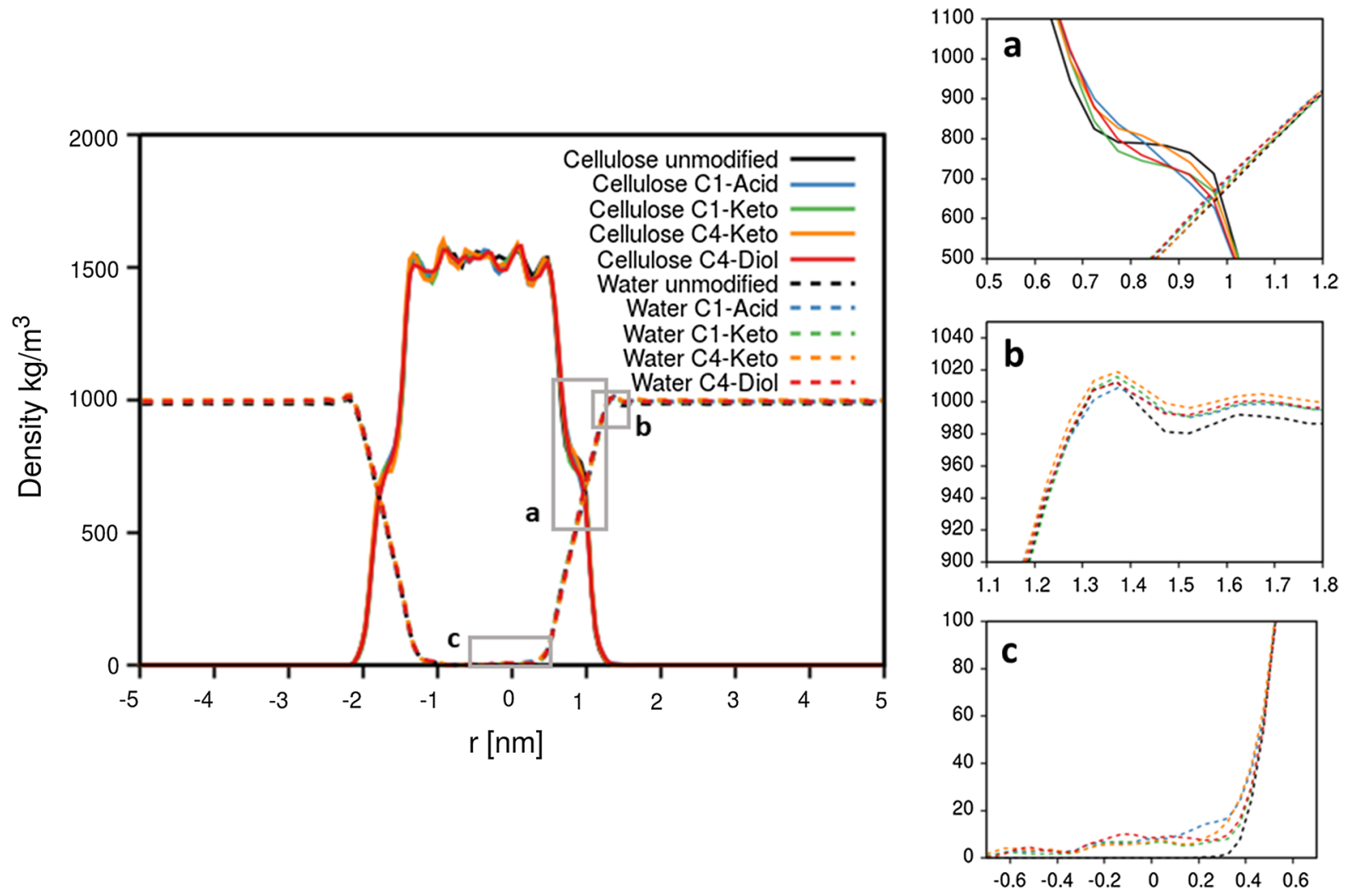

Fig. 8 Density profiles of cellulose and water at the $\{-100\}$ (negative $r$ ) and $\{100\}$ (positive $r$ ) interfaces. The distance axis $r$ is perpendicular to the crystal plane. The insets present enlargements of the data curve set so that inset $a$ presents the cellulose $\{100\}$-water interface, inset $b$ the structure of the two

data for the unoxidized glucose chain. The corresponding absolute numbers of hydrogen bonds have been presented in Fig. 6d. A single oxidation site results in similar interactions between the glucose chain and water for all examined oxidation defect types: oxidation increases $\mathrm{O} 2 \mathrm{H} 2$-water hydrogen bonds clearly, $\mathrm{O} 3 \mathrm{H} 3$ - water hydrogen bonds are unaffected, and O6H6-water hydrogen bonds decrease slightly. However, the $\mathrm{O} 2 \mathrm{H} 2$ groups have less hydrogen bonds with water than the $\mathrm{O} 3 \mathrm{H} 3$ and O6H6 groups. This means that the $\mathrm{O} 3 \mathrm{H} 3$ and $\mathrm{O} 6 \mathrm{H} 6$ groups have most interaction with water. The finding can be understood in terms of the chemical environment of the groups and their accessibility but it also provides means to tune water interactions.

Figure 9 plots the mean orientation $\Theta$ of the water molecules around either the $\mathrm{C} 1$ or $\mathrm{C} 4$ carbon as a function of distance $r$. Positive values of $\Theta$ correspond to water oxygen facing towards the reference carbon water layers at the $\{100\}$ interface, and inset $c$ the penetration of water molecules into the cellulose crystal structure. Data is presented for unmodified cellulose and systems with a single oxidation defect on the $\{100\}$ surface

atom, negative values to $\Theta$ correspond to water hydrogens facing towards the reference carbon. The data shows that water orientation around the oxidized carbon is dramatically different from intact cellulose. Furthermore, orientation of water is strongest around the $\mathrm{C} 1$-acid group, with two distinct water shells around the $\mathrm{C} 1$ carbon. This results from the localized negative charge of the carboxylic acid group. Altogether, the water orientation influence persists throughout the hydration layers meaning that the defects will influence hydration mediated interactions.

So far, the presented results and discussion address the effect of an individual defect on the cellulose crystal. Due to the periodicity in this type of simulations, actually the introduction of a single defect means that a defect density of $0.026 \mathrm{~nm}^{-2}$ was introduced to the system. To map the effect of this periodicity in the system, a comparison against a two times larger defect density was performed. In practice, 

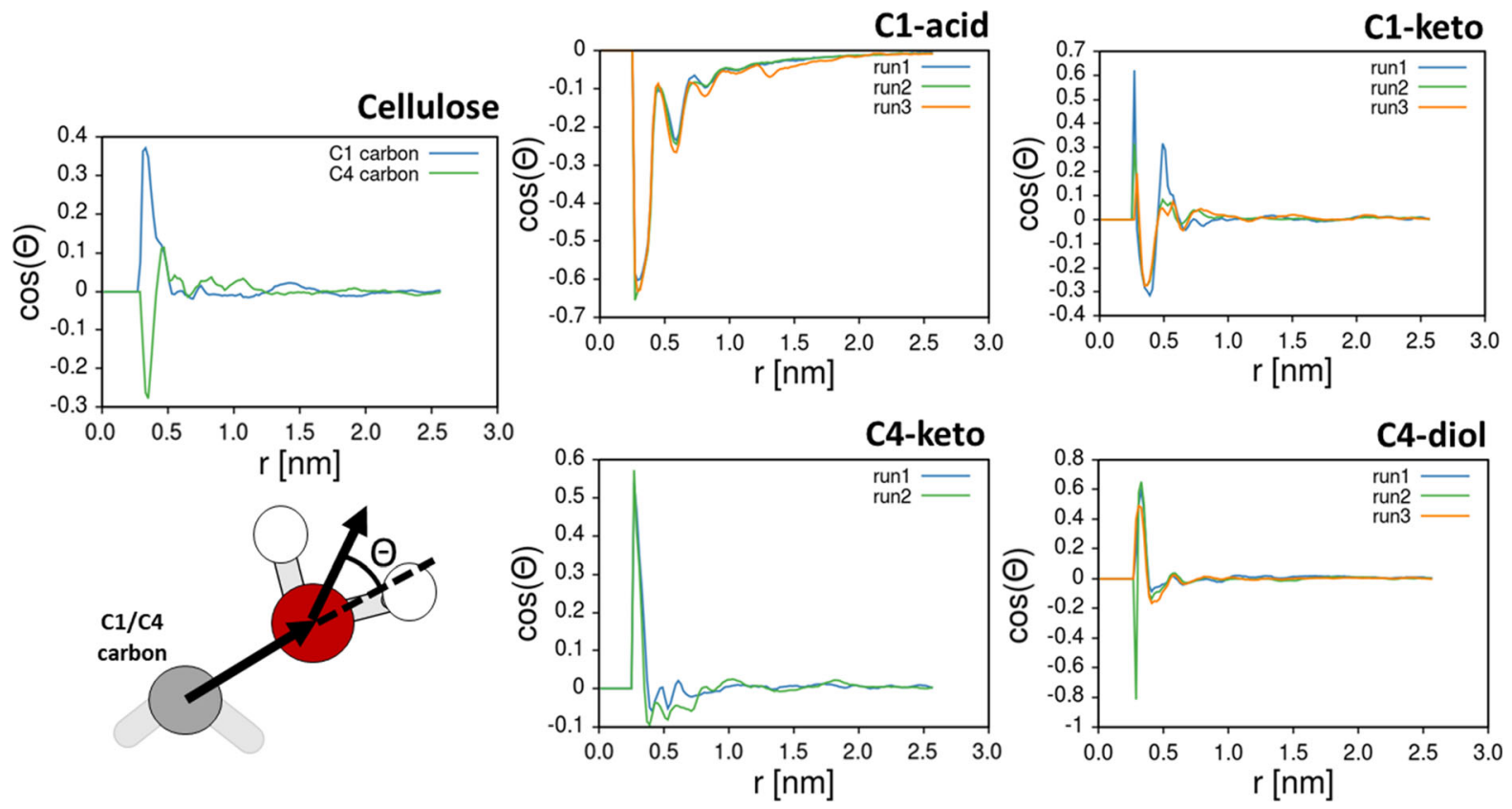

Fig. 9 Orientation of the water molecules around the oxidized carbon, either $\mathrm{C} 1$ (C1-acid and C1-keto) or C4 (C4-keto and C4diol) and a function of distance $r$. Positive values of $\Theta$

another defect site situated diagonally in another glucose chain on the surface plane as distanced as possible in the simulation box was introduced. The two oxidation sites were separated by 3 intact glucose chains and 3 intact glycosidic bonds, see Fig. 2. The data presented in Fig. 10 shows that doubling the defect density has little impact on the number of hydrogen bonds between the oxidized glucose chain and water, i.e. each introduced defect has an effect independent of the presence of the other defect. A small increase in hydrogen bonding with water with two oxidation defects can be seen for C1-keto, C4keto, and C4-diol. However, this effect, while systematic, falls within the range of the error bars. The findings indicate that point defects separated by several glucose chains and diagonally separated result in relatively independent destabilization effects on the crystal.

To resolve the separation at which the defects start interacting clearly, we turned to examining multiple oxidations in the same glucose chain. The oxidations were separated by either two, four, or six glucose rings. The introduction of two single site oxidations in the same chain essentially resulted in the simulations of glucose dimer, tetramer, and hexamer fragments correspond to water oxygen facing towards the reference carbon atom, negative values to $\Theta$ correspond to water hydrogens facing twords the reference carbon

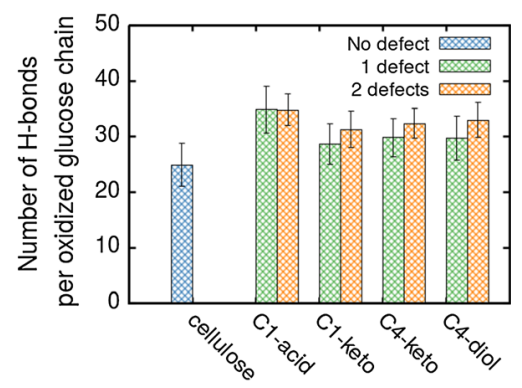

Fig. 10 Number of hydrogen bonds between the oxidized glucose chain and water when either one oxidation defect or two defects in different glucose chains are present on the cellulose surface. The error bars represent \pm standard deviation

that were not covalently bonded to the cellulose surface. Interestingly, the two smaller fragments, disaccharide and tetrasaccharide, become completely detached from the cellulose surface in all of the examined oxidation cases, i.e. C1-keto, C4-keto, C1acid and C4-diol oxidation, within the examined $150 \mathrm{~ns}$ simulation duration. The largest fragment, hexasaccharide did not detach from the surface within the simulated time scale. However, chain detachment in these molecular dynamics simulations is subject to thermal fluctuations of the system: even if the model 
would predict solubilization as the thermodynamically stable state, as the chain fragments are initially positioned at the cellulose crystal surface plane, their detachment and transfer to solution may not occur within the simulation time. Furthemore, diffusion of larger molecules takes longer time.

Two types of microcrystalline cellulose, i.e. Avicel and AaltoCell (crystallinity 82-84 \%), were used to experimentally study the range of soluble oxidized oligosaccharides that were released by a LPMO. The enzyme used in the study, Pc AA9D, catalyses cellulose oxidation at $\mathrm{C} 1$ position (Westereng et al. 2011). The HPAEC-PAD chromatograms of the range of soluble oxidized oligosaccharides released in treatment of Avicel and AaltoCell are shown in Fig. 11. Clearly more oxidized oligosaccharides were released from AaltoCell than Avicel, presumably be due to the significantly (ca $1.5 \times$ ) larger reactive surface area of AaltoCell compared to Avicel (Vanhatalo et al. 2016), which in turn is expected to increase accessibility of the cellulose to the enzyme. The large surface area combined with high crystallinity makes AaltoCell an excellent substrate for studying the enzyme action on ideal crystalline cellulose. Peaks corresponding to oxidized oligosaccharide with DP2-DP8 were detected, in accordance to data from (Westereng et al. 2013). The cellobionic acid (DP2ox) eluted very close to the cellohexaose (DP6), making conclusive separation difficult, see Supporting Information Figure S2 for an enlargement of the data region. In addition, smaller peaks corresponding to non-oxidized cellooligosaccharides with size of DP2-5 were seen (Fig. 11, full chromatograms in the Supporting Information as Figure S3).

Both the experimental and the simulational findings show that oxidations at sufficiently short separations inevitably lead to solubilization of the fragment. Overall, the findings are in agreement with aqueous solubility of short glucose oligomers, i.e. less than 6 glucose units oligomers being water soluble (Yu and Wu 2009; Sasaki et al. 2000; Cooke et al. 2002). This is consistent with decreased degree of hydration with increased glucose chain length (Arai and Shikata 2019).
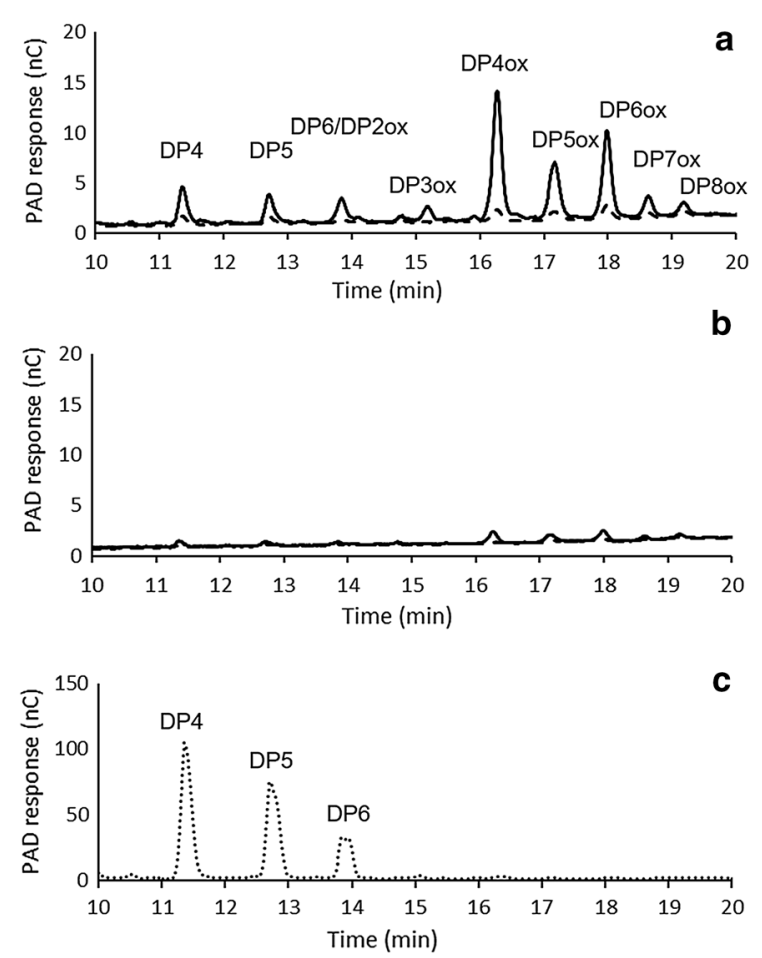

Fig. 11 HPAEC-PAD chromatograms of the soluble oligosaccharides (eluted within 10-20 min) released from (a) AaltoCell and (b) Avicel by LPMO Pc AA9D. Cellooligosaccharide standards with DP4-6 are shown in panel c. Full chromatograms can be found in the Supporting Information Figure S3

\section{Conclusions}

The structural and water interaction changes of crystalline cellulose $\{100\}$ surface due to oxidation point defects and the glucose fragment desorption resulting from oxidation point defects at close separations were explored using classical molecular dynamics simulations. The cellooligosaccharides solubilization findings were corroborated with experimental characterization of LPMO oxidation products on Avicel and AaltoCell substrates. We identify via the modelling how the breaking of glycosidic bonds causes local structural changes in the cellulose crystal and the surrounding water environment. In particular, the findings show that even single oxidations reduce the connections within the cellulose crystal and that the influence is mostly limited to interactions between the chains along the surface plane, locally, but that the oxidation defects also change the structure of the crystal in direction perpendicular to the surface. We analyse, which groups are most affected and propose 
changes in hydrogen bonding pattern likely to occur preceding chain desorption due to oxidation. Furthermore, we assess the water binding changes occurring due to oxidation defects: the defective surfaces bind a larger amount of water, which indicates increased hydrophilicity and stronger water interactions of cellulose crystals, even in the absence of full destabilization. Finally, both simulations and experiments indicate that LPMO induced oxidation defects induce solubilization of short glucose fragments with the experimental characterization showing fragments upto 8 glucose rings or shorter to solubilize. This reflects the water solubility of short cello-oligosaccharides.

As expected, oxidation decreases the interaction strength of the glucose chain with its neighboring chains. The simulations also show that oxidation causes local chain protrusions at the otherwise planar surface, makes the glucose chains significantly more flexible, and enhances structural fluctuations. Short glucose chain fragments can be expected to dissolve because of these effects; dissolvation is also expected based on literature ( $\mathrm{Yu}$ and $\mathrm{Wu}$ 2009; Sasaki et al. 2000; Cooke et al. 2002), consistent with the findings in this work. Furthermore, the defect induced protrusions may lead to enhanced accessibility of the glucose chains for e.g. cellulase enzymes, which further promotes the cellulose degradation process.

The defect induced protrusion and fluctuations of the glucose chain around the defect site effectively increase the solvent accessible surface area of the cellulose crystal, see Fig. 7. The defects also increase the hydrophilicity of the surface. In total, these influences lead to more water binding with the crystal and enhanced water interactions. Water accessibility increase is especially high for the $\mathrm{C} 1$-acid oxidation (carboxylic acid formation) but increases also for the other defects resulting from oxidation. However, even though the amount of water bound increases significantly by the defects, the defects have only local influence on the overall water structure. This results from their point-like nature: water forms similar ordered layers on the cellulose surface both for intact and point defect containing cellulose crystal surfaces.

Consistent with our findings, water binding to cellulose has been previously shown experimentally to be highly region specific (Hofstetter et al. 2006; Felby et al. 2008; Velazquez et al. 2003). While not directly observed here, the water interacting with the cellulose surface is subject to division to interfacial and bulk- like water populations (O'Neill et al. 2017). It is plausible that differences the amount of interfacial water connect with cellulose crystal interactions. For example, for other hydrated macromolecular systems, interfacial water, in comparison to bulk water, connects with decreasing plasticity of the material (Batys et al. 2018, 2019; Suarez-Martinez et al. 2019).

Furthermore, we assessed the correlations of defects in different glucose chains: when separated by several glucose chains, the effect of the point defects is practically independent of the presence of other defects in the system. However, increase in number of oxidation defects quite expectedly decreases the interactions within cellulose further and in proportion to defect density. Correlations in the influence of multiple defects however, were clearly observed when multiple oxidations were placed in same glucose chain. The simulation findings show that high oxidation site concentration will cause small oligosacharides (the examined di- and tetrasaccharides) to completely detach from the cellulose surface. Experimentally, detached chains up to 8 glucose units in length were observed. Additionally, a comparison of the Avicel and AaltoCell data points toward the reactive surface area in addition to crystallinity being a significant factor in efficiency of enzymatic cleavage via the LPMOs.

Overall, these results give information about the effect of oxidation induced defects on cellulose and surrounding water structure. As enzymatic conversion of crystalline cellulose is highly useful in developing processing means toward economically and environmentally sustainable biofuels and chemicals, such information could aid in designing refining processes. The findings improve understanding of the structural features rising from oxidation in crystalline cellulose, the oxidation process by LPMO, and also efficiency of the oxidation treatment.

Acknowledgments The authors acknowledge that this work was a part of the Academy of Finland's Flagship Programme under Project Nos. 318890 and 318891 (Competence Center for Materials Bioeconomy, FinnCERES). The work was also supported by Academy of Finland Grant Nos. 309324, 311608 and 326262 and Business Finland BioAd-FiDiPro project (2015-2019; Dnro 1918/31/2015). Authors also gratefully acknowledge CSC-IT Center for Science, Finland, and RAMI-RawMatTERS Finland Infrastructure for computational resources. 
Open Access This article is licensed under a Creative Commons Attribution 4.0 International License, which permits use, sharing, adaptation, distribution and reproduction in any medium or format, as long as you give appropriate credit to the original author(s) and the source, provide a link to the Creative Commons licence, and indicate if changes were made. The images or other third party material in this article are included in the article's Creative Commons licence, unless indicated otherwise in a credit line to the material. If material is not included in the article's Creative Commons licence and your intended use is not permitted by statutory regulation or exceeds the permitted use, you will need to obtain permission directly from the copyright holder. To view a copy of this licence, visit http://creativecommons.org/licenses/by/4.0/.

Funding Funding provided by Academy of Finland. Open access funding provided by Aalto University.

\section{References}

Abraham MJ, Murtola T, Schulz R, Pall S, Smith JC, Hess B, Lindahl E (2015) Gromacs: high performance molecular simulations through multi-level parallelism from laptops to supercomputers. SoftwareX 1-2:19-25

Agger JW, Isaksen T, Varnai A, Vidal-Melgosa S, Willats WG, Ludwig R, Horn SJ, Eijsink VG, Westereng B (2014) Discovery of LPMO activity on hemicelluloses shows the importance of oxidative processes in plant cell wall degradation. Proc Natl Acad Sci USA 111(17):6287-6292

Arai K, Shikata T (2019) Molecular motions, structure and hydration behaviour of glucose oligomers in aqueous solution. Phys Chem Chem Phys 21(45):25,379-25,388

Atalla RH, Vanderhart DL (1984) Native cellulose: a composite of two distinct crystalline forms. Science 223(4633):283-285

Batys P, Kivisto S, Lalwani SM, Lutkenhaus JL, Sammalkorpi M (2019) Comparing water-mediated hydrogen-bonding in different polyelectrolyte complexes. Soft Matter 15(39):7823-7831

Batys P, Zhang YP, Lutkenhaus JL, Sammalkorpi M (2018) Hydration and temperature response of water mobility in poly(diallyldimethylammonium)-poly(sodium 4-styrenesulfonate) complexes. Macromolecules 51(20):8268-8277

Beeson WT, Phillips CM, Cate JH, Marletta MA (2012) Oxidative cleavage of cellulose by fungal copper-dependent polysaccharide monooxygenases. J Am Chem Soc 134(2):890-892

Bellesia G, Chundawat SP, Langan P, Redondo A, Dale BE, Gnanakaran S (2012) Coarse-grained model for the interconversion between native and liquid ammonia-treated crystalline cellulose. J Phys Chem B 116(28):8031-8037

Bennati-Granier C, Garajova S, Champion C, Grisel S, Haon M, Zhou S, Fanuel M, Ropartz D, Rogniaux H, Gimbert I, Record E, Berrin JG (2015) Substrate specificity and regioselectivity of fungal AA9 lytic polysaccharide monooxygenases secreted by Podospora anserina. Biotechnol Biofuels 8:90
Bergenstrahle M, Berglund LA, Mazeau K (2007) Thermal response in crystalline Ibeta cellulose: a molecular dynamics study. J Phys Chem B 111(30):9138-9145

Bergenstrahle M, Thormann E, Nordgren N, Berglund LA (2009) Force pulling of single cellulose chains at the crystalline cellulose-liquid interface: a molecular dynamics study. Langmuir 25(8):4635-4642

Bhat MK, Bhat S (1997) Cellulose degrading enzymes and their potential industrial applications. Biotechnol Adv 15(3-4):583-620

Biely P, Singh S, Puchart V (2016) Towards enzymatic breakdown of complex plant xylan structures: state of the art. Biotechnol Adv 34(7):1260-1274

Biermann O, Hadicke E, Koltzenburg S, Muller-Plathe F (2001) Hydrophilicity and lipophilicity of cellulose crystal surfaces. Angew Chem Int Ed Engl 40(20):3822-3825

Busk PK, Lange L (2015) Classification of fungal and bacterial lytic polysaccharide monooxygenases. BMC Genom $16: 368$

Bussi G, Donadio D, Parrinello M (2007) Canonical sampling through velocity rescaling. J Chem Phys 126(1):014,101

Calero C, Martí J, Guàrdia E (2015) 1h nuclear spin relaxation of liquid water from molecular dynamics simulations. J Phys Chem B 119(5):1966-1973

Cao Y, Wu J, Zhang J, Li H, Zhang Y, He J (2009) Room temperature ionic liquids (RTILs): a new and versatile platform for cellulose processing and derivatization. Chem Eng J 147(1):13-21

Chundawat SP, Bellesia G, Uppugundla N, da Costa Sousa L, Gao D, Cheh AM, Agarwal UP, Bianchetti CM, Phillips GN, Langan P, Balan V, Gnanakaran S, Dale BE (2011) Restructuring the crystalline cellulose hydrogen bond network enhances its depolymerization rate. J Am Chem Soc 133(29):11,163-11,174

Cooke SA, Jónsdóttir SO, Westh P (2002) A thermodynamic study of glucose and related oligomers in aqueous solution: Vapor pressures and enthalpies of mixing. J Chem Eng Data 47(5):1185-1192

Couturier M, Ladeveze S, Sulzenbacher G, Ciano L, Fanuel M, Moreau C, Villares A, Cathala B, Chaspoul F, Frandsen KE, Labourel A, Herpoel-Gimbert I, Grisel S, Haon M, Lenfant N, Rogniaux H, Ropartz D, Davies GJ, Rosso MN, Walton PH, Henrissat B, Berrin JG (2018) Lytic xylan oxidases from wood-decay fungi unlock biomass degradation. Nat Chem Biol 14(3):306-310

Darden T, York D, Pedersen L (1993) Particle mesh Ewald: an $\mathrm{N} \log (\mathrm{N})$ method for Ewald sums in large systems. J Chem Phys 98(12):10,089-10,092

Eichhorn S, Davies G (2006) Modelling the crystalline deformation of native and regenerated cellulose. Cellulose 13(3):291-307

Felby C, Thygesen LG, Kristensen JB, Jørgensen H, Elder T (2008) Cellulose-water interactions during enzymatic hydrolysis as studied by time domain nmr. Cellulose 15:703-710

Forsberg Z, Mackenzie AK, Sorlie M, Rohr AK, Helland R, Arvai AS, Vaaje-Kolstad G, Eijsink VG (2014) Structural and functional characterization of a conserved pair of bacterial cellulose-oxidizing lytic polysaccharide monooxygenases. Proc Natl Acad Sci USA 111(23):8446-8451 
Forsberg Z, Vaaje-Kolstad G, Westereng B, Bunaes AC, Stenstrom Y, MacKenzie A, Sorlie M, Horn SJ, Eijsink VG (2011) Cleavage of cellulose by a CBM33 protein. Protein Sci 20(9):1479-1483

Frandsen KE, Simmons TJ, Dupree P, Poulsen JC, Hemsworth GR, Ciano L, Johnston EM, Tovborg M, Johansen KS, von Freiesleben P, Marmuse L, Fort S, Cottaz S, Driguez H, Henrissat B, Lenfant N, Tuna F, Baldansuren A, Davies GJ, Lo Leggio L, Walton PH (2016) The molecular basis of polysaccharide cleavage by lytic polysaccharide monooxygenases. Nat Chem Biol 12(4):298-303

Frommhagen M, Sforza S, Westphal AH, Visser J, Hinz SW, Koetsier MJ, van Berkel WJ, Gruppen H, Kabel MA (2015) Discovery of the combined oxidative cleavage of plant xylan and cellulose by a new fungal polysaccharide monooxygenase. Biotechnol Biofuels 8:101

Gomes TC, Skaf MS (2012) Cellulose-builder: a toolkit for building crystalline structures of cellulose. J Comput Chem 33(14): 1338-1346

Guvench O, Mallajosyula SS, Raman EP, Hatcher E, Vanommeslaeghe K, Foster TJ, Jamison FW, Mackerell AD (2011) CHARMM additive all-atom force field for carbohydrate derivatives and its utility in polysaccharide and carbohydrate-protein modeling. J Chem Theor Comput 7(10):3162-3180

Harris PV, Welner D, McFarland KC, Re E, Navarro Poulsen JC, Brown K, Salbo R, Ding H, Vlasenko E, Merino S, Xu F, Cherry J, Larsen S, Lo Leggio L (2010) Stimulation of lignocellulosic biomass hydrolysis by proteins of glycoside hydrolase family 61: structure and function of a large, enigmatic family. Biochemistry 49(15):3305-3316

Hayashi N, Kondo T, Ishihara M (2005) Enzymatically produced nano-ordered short elements containing cellulose I $\beta$ crystalline domains. Carbohydr Polym 61(2):191-197

Heiner AP, Teleman O (1997) Interface between monoclinic crystalline cellulose and water: breakdown of the odd/even duplicity. Langmuir 13(3):511-518

Heiner AP, Kuutti L, Teleman O (1998) Comparison of the interface between water and four surfaces of native crystalline cellulose by molecular dynamics simulations. Carbohydr Res 306(1):205-220

Henriksson M, Henriksson G, Berglund L, Lindström T (2007) An environmentally friendly method for enzyme-assisted preparation of microfibrillated cellulose (MFC) nanofibers. Eur Polym J 43(8):3434-3441

Hess B, Bekker H, Berendsen HJC, Fraaije JGEM (1997) Lincs: a linear constraint solver for molecular simulations. J Comput Chem 18(12):1463-1472

Himmel ME, Ding SY, Johnson DK, Adney WS, Nimlos MR, Brady JW, Foust TD (2007) Biomass recalcitrance: engineering plants and enzymes for biofuels production. Science 315(5813):804-807

Hofstetter K, Hinterstoisser B, Salmen L (2006) Moisture uptake in native cellulose the roles of different hydrogen bonds: a dynamic FT-IR study using deuterium exchange. Cellulose 13:131-145

Horn SJ, Vaaje-Kolstad G, Westereng B, Eijsink VG (2012) Novel enzymes for the degradation of cellulose. Biotechnol Biofuels 5(1):45

Humphrey W, Dalke A, Schulten K (1996) VMD: visual molecular dynamics. J Mol Graph 14(1):33-38
Isaksen T, Westereng B, Aachmann FL, Agger JW, Kracher D, Kittl R, Ludwig R, Haltrich D, Eijsink VG, Horn SJ (2014) A C4-oxidizing lytic polysaccharide monooxygenase cleaving both cellulose and cello-oligosaccharides. J Biol Chem 289(5):2632-2642

Isogai A (2018) Development of completely dispersed cellulose nanofibers. Proc Jpn Acad Ser B Phys Biol Sci 94(4):161-179

Isogai A, Saito T, Fukuzumi H (2011) TEMPO-oxidized cellulose nanofibers. Nanoscale 3(1):71-85

Jorgensen WL, Chandrasekhar J, Madura JD, Impey RW, Klein ML (1983) Comparison of simple potential functions for simulating liquid water. J Chem Phys 79(2):926-935

Jüergensen J, Ilmberger N, Streit WR (2012) Screening for cellulases with industrial value and their use in biomass conversion. Methods Mol Biol 834:1-16

Khalil HA, Bhat A, Yusra AI (2012) Green composites from sustainable cellulose nanofibrils: a review. Carbohydr Polym 87(2):963-979

Kontturi E, Tammelin T, Österberg M (2006) Cellulose-model films and the fundamental approach. Chem Soc Rev 35:1287-1304

Kubicki J, Watts H, Zhao Z, Zhong L (2013) Quantum mechanical calculations on cellulose-water interactions: structures, energetics, vibrational frequencies and NMR chemical shifts for surfaces of $\mathrm{I} \alpha$ and $\mathrm{I} \beta$ cellulose. Cellulose 21:909-926.

Kumar S, Gupta R, Lee YY, Gupta RB (2010) Cellulose pretreatment in subcritical water: effect of temperature on molecular structure and enzymatic reactivity. Bioresour Technol 101(4):1337-1347

Langan P, Sukumar N, Nishiyama Y, Chanzy H (2005) Synchrotron $\mathrm{X}$-ray structures of cellulose $\mathrm{I} \beta$ and regenerated cellulose II at ambient temperature and $100 \mathrm{~K}$. Cellulose 12(6):551-562

Langston JA, Shaghasi T, Abbate E, Xu F, Vlasenko E, Sweeney MD (2011) Oxidoreductive cellulose depolymerization by the enzymes cellobiose dehydrogenase and glycoside hydrolase 61. Appl Environ Microbiol 77(19):7007-7015

Larsson PT, Wickholm K, Iversen T (1997) A CP/MAS13C NMR investigation of molecular ordering in celluloses. Carbohydr Res 302(1):19-25

Li Y, Lin M, Davenport JW (2011) Ab initio studies of cellulose i: crystal structure, intermolecular forces, and interactions with water. J Phys Chem C 115(23):11,533-11,539

Li YJ, Lu YY, Zhang ZJ, Mei S, Tan TW, Fan LH (2017) Cofermentation of cellulose and sucrose/xylose by engineered yeasts for bioethanol production. Energy Fuels 31(4):4061-4067

Li Y, Wang J, Liu X, Zhang S (2018) Towards a molecular understanding of cellulose dissolution in ionic liquids: anion/cation effect, synergistic mechanism and physicochemical aspects. Chem Sci 9(17):4027-4043

Lindman B, Karlström G, Stigsson L (2010) On the mechanism of dissolution of cellulose. J Mol Liq 156(1):76-81

Liu B, Krishnaswamyreddy S, Muraleedharan MN, Olson A, Broberg A, Stahlberg J, Sandgren M (2018) Side-by-side biochemical comparison of two lytic polysaccharide monooxygenases from the white-rot fungus Heterobasidion irregulare on their activity against crystalline cellulose and glucomannan. PLoS ONE 13(9):e0203,430 
Lo Leggio L, Simmons TJ, Poulsen JC, Frandsen KE, Hemsworth GR, Stringer MA, von Freiesleben P, Tovborg M, Johansen KS, De Maria L, Harris PV, Soong CL, Dupree P, Tryfona T, Lenfant N, Henrissat B, Davies GJ, Walton PH (2015) Structure and boosting activity of a starch-degrading lytic polysaccharide monooxygenase. Nat Commun 6:5961

Mahoney MW, Jorgensen WL (2000) A five-site model for liquid water and the reproduction of the density anomaly by rigid, nonpolarizable potential functions. J Chem Phys 112(20):8910-8922.

Mallajosyula SS, Guvench O, Hatcher E, Mackerell AD (2012) CHARMM additive all-atom force field for phosphate and sulfate linked to carbohydrates. J Chem Theor Comput 8(2):759-776

Matthews JF, Beckham GT, Bergenstrahle-Wohlert M, Brady JW, Himmel ME, Crowley MF (2012) Comparison of cellulose I $\beta$ simulations with three carbohydrate force fields. J Chem Theory Comput 8(2):735-748

Matthews J, Skopec C, Mason P, Zuccato P, Torget R, Sugiyama J, Himmel M, Brady J (2006) Computer simulation studies of microcrystalline cellulose I $\beta$. Carbohydr Res $341: 138-152$

Mazeau K (2005) Structural micro-heterogeneities of crystalline I $\beta$-cellulose. Cellulose 12(4):339-349

Mazeau K, Heux L (2003) Molecular dynamics simulations of bulk native crystalline and amorphous structures of cellulose. J Phys Chem B 107(10):2394-2403

Mazeau K, Rivet A (2008) Wetting the (110) and (100) surfaces of Ibeta cellulose studied by molecular dynamics. Biomacromolecules 9(4):1352-1354

Miyamoto H, Schnupf U, Crowley MF, Brady JW (2016) Comparison of the simulations of cellulosic crystals with three carbohydrate force fields. Carbohydr Res 422:17-23

Moon RJ, Martini A, Nairn J, Simonsen J, Youngblood J (2011) Cellulose nanomaterials review: structure, properties and nanocomposites. Chem Soc Rev 40(7):3941-3994

Nawrocki G, Cazade PA, Thompson D, Cieplak M (2015) Peptide recognition capabilities of cellulose in molecular dynamics simulations. J Phys Chem C 119(43):24,404-24,416

Nekiunaite L, Petrovic DM, Westereng B, Vaaje-Kolstad G, Hachem MA, Varnai A, Eijsink VG (2016) FgLPMO9A from Fusarium graminearum cleaves xyloglucan independently of the backbone substitution pattern. FEBS Lett 590(19):3346-3356

Nishino T, Matsuda I, Hirao K (2004) All-cellulose composite. Macromolecules 37(20):7683-7687

Nishiyama Y, Johnson GP, French AD, Forsyth VT, Langan P (2008) Neutron crystallography, molecular dynamics, and quantum mechanics studies of the nature of hydrogen bonding in cellulose $\mathrm{I} \beta$. Biomacromolecules 9(11):3133-3140

Nishiyama Y, Langan P, Chanzy H (2002) Crystal structure and hydrogen-bonding system in cellulose $\mathrm{I} \beta$ from synchrotron $\mathrm{X}$-ray and neutron fiber diffraction. J Am Chem Soc 124(31):9074-9082

Oehme DP, Downton MT, Doblin MS, Wagner J, Gidley MJ, Bacic A (2015) Unique aspects of the structure and dynamics of elementary $\mathrm{I} \beta$ cellulose microfibrils revealed by computational simulations. Plant Physiol 168(1):3-17
Oehme DP, Yang H, Kubicki JD (2018) An evaluation of the structures of cellulose generated by the CHARMM force field: comparisons to in planta cellulose. Cellulose 25(7):3755-3777

O’Neill H, Pingali SV, Petridis L, He J, Mamontov E, Hong L, Urban V, Evans B, Langan P, Smith JC, Davison BH (2017) Dynamics of water bound to crystalline cellulose. Sci Rep 7:11840

Paliwal R, Rawat AP, Rawat M, Rai JP (2012) Bioligninolysis: recent updates for biotechnological solution. Appl Biochem Biotechnol 167(7):1865-1889

Parrinello M, Rahman A (1981) Polymorphic transitions in single-crystals: a new molecular-dynamics method. J Appl Phys 52(12):7182-7190

Parrinello M, Rahman A, Vashishta P (1983) Structural transitions in superionic conductors. Phys Rev Lett 50(14):1073-1076

Phillips CM, Beeson WT, Cate JH, Marletta MA (2011) Cellobiose dehydrogenase and a copper-dependent polysaccharide monooxygenase potentiate cellulose degradation by Neurospora crassa. ACS Chem Biol 6(12):1399-1406

Prates ET, Stankovic I, Silveira RL, Liberato MV, HenriqueSilva F, Pereira N, Polikarpov I, Skaf MS (2013) X-ray structure and molecular dynamics simulations of endoglucanase 3 from Trichoderma harzianum: structural organization and substrate recognition by endoglucanases that lack cellulose binding module. PLoS ONE 8(3):e59,069

Pronk S, Pall S, Schulz R, Larsson P, Bjelkmar P, Apostolov R, Shirts MR, Smith JC, Kasson PM, van der Spoel D, Hess B, Lindahl E (2013) GROMACS 4.5: a high-throughput and highly parallel open source molecular simulation toolkit. Bioinformatics 29(7):845-854

Quinlan RJ, Sweeney MD, Lo Leggio L, Otten H, Poulsen JC, Johansen KS, Krogh KB, Jorgensen CI, Tovborg M, Anthonsen A, Tryfona T, Walter CP, Dupree P, Xu F, Davies GJ, Walton PH (2011) Insights into the oxidative degradation of cellulose by a copper metalloenzyme that exploits biomass components. Proc Natl Acad Sci USA 108(37):15,079-15,084

Raman EP, Guvench O, MacKerell AD (2010) CHARMM additive all-atom force field for glycosidic linkages in carbohydrates involving furanoses. J Phys Chem B 114(40):12,981-12,994

Sasaki M, Fang Z, Fukushima Y, Adschiri T, Arai K (2000) Dissolution and hydrolysis of cellulose in subcritical and supercritical water. Ind Eng Chem Res 39(8):2883-2890

Suarez-Martinez PC, Batys P, Sammalkorpi M, Lutkenhaus JL (2019) Time-temperature and time-water superposition principles applied to poly(allylamine)/poly(acrylic acid) complexes. Macromolecules 52(8):3066-3074

Sugiyama J, Vuong R, Chanzy H (1991) Electron diffraction study on the two crystalline phases occurring in native cellulose from an algal cell wall. Macromolecules 24(14):4168-4175

Tan TC, Kracher D, Gandini R, Sygmund C, Kittl R, Haltrich D, Hallberg BM, Ludwig R, Divne C (2015) Structural basis for cellobiose dehydrogenase action during oxidative cellulose degradation. Nat Commun 6:7542

Vaaje-Kolstad G, Westereng B, Horn SJ, Liu Z, Zhai H, Sorlie M, Eijsink VG (2010) An oxidative enzyme boosting the 
enzymatic conversion of recalcitrant polysaccharides. Science 330(6001):219-222

VanderHart DL, Atalla RH (1987) Further carbon-13 NMR evidence for the coexistence of two crystalline forms in native celluloses, Chap 5. In: The structures of cellulose. ACS symposium series, vol 340. American Chemical Society, USA, pp 88-118

Vanhatalo K, Dahl O (2014) Effect of mild acid hydrolysis parameters on properties of microcrystalline cellulose. BioResources 9(47):4729-4740

Vanhatalo K, Maximova N, Perander AM, Johansson LS, Haimi E, Dahl O (2016) Comparison of conventional and ligninrich microcrystalline cellulose. BioResources 11(2):4037-4054

Vega C, Abascal JL (2011) Simulating water with rigid nonpolarizable models: a general perspective. Phys Chem Chem Phys 13(44):19,663-19,688

Velazquez G, Herrera-Gomez A, Martin-Polo M (2003) Identification of bound water through infrared spectroscopy in methylcellulose. J Food Eng 59(1):79-84

Vermaas JV, Crowley MF, Beckham GT, Payne CM (2015) Effects of lytic polysaccharide monooxygenase oxidation on cellulose structure and binding of oxidized cellulose oligomers to cellulases. J Phys Chem B 119(20):6129-6143

Vietor RJ, Newman RH, Ha MA, Apperley DC, Jarvis MC (2002) Conformational features of crystal-surface cellulose from higher plants. Plant J 30(6):721-731

Ward OP, Moo-Young M (1989) Enzymatic degradation of cell wall and related plant polysaccharides. Crit Rev Biotechnol 8(4):237-274

Westereng B, Ishida T, Vaaje-Kolstad G, Wu M, Eijsink VG, Igarashi K, Samejima M, Stahlberg J, Horn SJ, Sandgren M (2011) The putative endoglucanase PcGH61D from Phanerochaete chrysosporium is a metal-dependent oxidative enzyme that cleaves cellulose. PLoS ONE 6(11):e27,807

Westereng B, Agger JW, Horn SJ, Vaaje-Kolstad G, Aachmann FL, Stenstrøm YH, Eijsink VG (2013) Efficient separation of oxidized cello-oligosaccharides generated by cellulose degrading lytic polysaccharide monooxygenases. J Chromatogr A 1271(1):144-152

Yu Y, Wu H (2009) Characteristics and precipitation of glucose oligomers in the fresh liquid products obtained from the hydrolysis of cellulose in hot-compressed water. Ind Eng Chem Res 48(23): 10,682-10,690

Yui T, Hayashi S (2007) Molecular dynamics simulations of solvated crystal models of cellulose I(alpha) and III(I). Biomacromolecules 8(3):817-824

Yui T, Nishimura S, Akiba S, Hayashi S (2006) Swelling behavior of the cellulose Ibeta crystal models by molecular dynamics. Carbohydr Res 341(15):2521-2530

Zhao X, Rignall TR, McCabe C, Adney WS, Himmel ME (2008) Molecular simulation evidence for processive motion of trichoderma reesei Cel7A during cellulose depolymerization. Chem Phys Lett 460(1):284-288

Zhao X, Xiong L, Zhang M, Bai F (2016) Towards efficient bioethanol production from agricultural and forestry residues: Exploration of unique natural microorganisms in combination with advanced strain engineering. Bioresour Technol 215:84-91

Zimmermann T, Bordeanu N, Strub E (2010) Properties of nanofibrillated cellulose from different raw materials and its reinforcement potential. Carbohydr Polym 79(4):1086-1093

Publisher's Note Springer Nature remains neutral with regard to jurisdictional claims in published maps and institutional affiliations. 